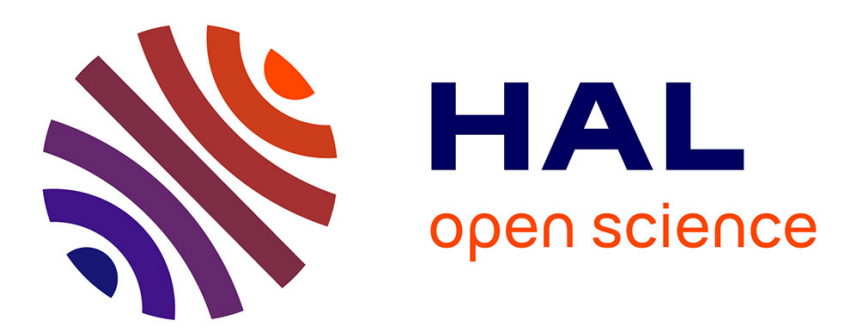

\title{
Identification of elastic parameters by displacement field measurement
}

Giuseppe Geymonat, François Hild, Stéphane Pagano

\section{To cite this version:}

Giuseppe Geymonat, François Hild, Stéphane Pagano. Identification of elastic parameters by displacement field measurement. Comptes Rendus Mécanique, 2002, 330, pp.403-408. 10.1016/S16310721(02)01476-6 . hal-00002934v2

\section{HAL Id: hal-00002934 \\ https://hal.science/hal-00002934v2}

Submitted on 24 Sep 2004

HAL is a multi-disciplinary open access archive for the deposit and dissemination of scientific research documents, whether they are published or not. The documents may come from teaching and research institutions in France or abroad, or from public or private research centers.
L'archive ouverte pluridisciplinaire HAL, est destinée au dépôt et à la diffusion de documents scientifiques de niveau recherche, publiés ou non, émanant des établissements d'enseignement et de recherche français ou étrangers, des laboratoires publics ou privés. 


\title{
Identification of elastic parameters by displacement field measurement
}

\author{
Giuseppe Geymonat $^{\text {a }}$, François Hild ${ }^{\text {b }}$, Stéphane Pagano ${ }^{\text {a }}$ \\ a LMGC, CNRS-Université de Montpellier II, Place E. Bataillon CC048 34005 Montpellier Cedex \\ E-mail: \{geymonat,pagano\}@Imgc.univ-montp2.fr \\ b LMT-Cachan, ENS de Cachan / CNRS UMR 8535 / Université Paris 6, 61 Avenue du Président Wilson, \\ 94235 Cachan Cedex \\ E-mail: hild@Imt.ens-cachan.fr
}

(Reçu le jour mois année, accepté après révision le jour mois année)

\begin{abstract}
In this Note we study a parameter identification problem associated with a two-dimensional mechanical problem. In a first part, the experimental technique of determining the displacement field is presented. The variational method proposed herein is based on the minimization of a separately convex functional which leads to the reconstruction of the elastic tensor and the stress field. These two reconstructed fields are continuous and piecewise linear on a triangulation of the two-dimensional problem. Some numerical and experimental examples are presented to test the performance of the algorithm. (C) 2001 Académie des sciences/Éditions scientifiques et médicales Elsevier SAS

Continuum mechanics/ identification/ inverse problem/ digital image correlation
\end{abstract}

Identification de paramètres mécaniques par mesure de champ de déplacement

Résumé. On étudie un problème d'identification de paramètres associés à des équations de la mécanique en dimension 2. Pour cela, dans une première partie, on présente le procédé expérimental permettant de mesurer le champ de déplacements. La méthode variationnelle proposée est basée sur la minimisation d'une fonctionnelle séparement convexe et permet de reconstruire à la fois le tenseur d'élasticité et le champ des contraintes à partir des mesures $d u$ champ de déplacements. Les deux champs reconstruits sont continus et linéaires par morceaux sur une triangulation du domaine bidimensionnel. Pour tester les performances de l'algorithme on présente des exemples numériques et expérimentaux. (C) 2001 Académie des sciences/Éditions scientifiques et médicales Elsevier SAS

Milieux continus/identification/problème inverse/ corrélation d'images numériques

\section{Version française abrégée}

Pour déterminer un champ de déplacement d'une texture aléatoire en cours d'essai, on peut acquérir des images pour lesquelles on analyse une série de sous-images (ou encore zones d'étude, ZE) de la région Note présentée par First name NAME

S1620-7742(01)0????-?/FLA

(C) 2001 Académie des sciences/Éditions scientifiques et médicales Elsevier SAS. Tous droits réservés. 


\section{G. Geymonat, F. Hild, S. Pagano}

d'étude (RE). Le but de la corrélation est d'apparier les ZE entre elles dans les deux images. Le déplacement est alors un décalage bidimensionnel d'un signal. On considère dans l'équation (1) un signal $g(\mathbf{x})$, qui est le décalé d'un signal de référence $f(\mathbf{x})$ bruité par $b(\mathbf{x})$ (cf. [4] dans le cas de caméras $\mathrm{CCD}$ ), où $\mathbf{u}$ est le déplacement inconnu que l'on cherche à identifier. L'évaluation de $\mathbf{u}$ revient à minimiser la norme de la différence (2) par rapport à un déplacement test v. Lorsque l'on choisit la norme quadratique usuelle, cette minimisation est équivalente à maximiser $h(\mathbf{v})$ (3), où $\star$ est le produit d'intercorrélation. Le déplacement qui maximise le produit d'intercorrélation est noté $\mathbf{u}^{*}$. Un algorithme sub-pixel basé sur des transformées de Fourier rapides est utilisé [1].

La figure 1 montre des mesures de déformations obtenues à l'aide de jauges et une comparaison avec des prévisions obtenues par corrélation d'images numériques $(1008 \times 1016$ pixels, codage sur 8 bits $)$. Les déformations longitudinale et transversale ont été mesurées lors d'un essai de traction sur une éprouvette en AU4G avec un montage spécial [3]. Un microscope longue distance permet d'examiner une surface de $4 \mathrm{~mm}^{2}$. Une taille de ZE de $64 \times 64$ pixels a été utilisée. L'écart quadratique moyen de l'erreur entre mesure par jauge et par corrélation d'images est de $6 \times 10^{-5}$. Des déformations de l'ordre de $10^{-4}$ peuvent être mesurées de manière fiable. A l'aide de ces mesures par corrélation d'images on a obtenu un module d'Young de $72 \pm 3 \mathrm{GPa}$ et un coefficient de Poisson de $0.3 \pm 0.03$ pour des contraintes moyennes variant de 10 à $90 \mathrm{MPa}$. Ces valeurs sont en concordance avec celles données pour ce type d'alliage [7] (72 GPa et 0.32 , respectivement) et avec celles déduites des mesures par jauges (76 $\pm 0.5 \mathrm{GPa}$ et $0.33 \pm 0.005$, respectivement).

On peut donc considérer qu'avec ces mesures on connait le champ des déplacements plans $\mathbf{u}^{*} \in\left(\mathrm{H}^{1}(\Omega)\right)^{2}$, où $\Omega \subset \mathbb{R}^{2}$ représente la RE. De même, on suppose connue la densité des forces volumiques et que des observations (linéaires) $L$ sur l'effort appliqué durant l'essai (cf. équation (4); par exemple, le niveau d'effort global lors d'un essai de traction peut être considéré comme une observation linéaire du champ de contrainte inconnu $\boldsymbol{\sigma}$ ). L'objectif principal de ce qui suit est de trouver le tenseur d'élasticité associé et le champ de contrainte sans hypothèses supplémentaires (en particulier d'homogénéité de l'essai). Moyennant ces données, on dira qu'un couple $(\mathbf{A}, \boldsymbol{\sigma})$, où $\mathbf{A}$ est le tenseur des complaisances élastiques, est solution du problème d'identification s'il satisfait les relations (4), (5) et (6).

Le champ des contraintes admissibles, noté $\Sigma_{a d m}$, est défini par (7). En ce qui concerne le champ des tenseurs de complaisance admissibles, noté $\mathcal{E}$, on peut choisir, par exemple, l'ensemble des tenseurs à coefficients constants $\left(\mathcal{E}_{1}\right)$ ou linéaire par morceaux $\left(\mathcal{E}_{2}\right)$. Avec ces notations, on peut montrer que la fonctionnelle $F(\boldsymbol{\tau}, \mathbf{A})$ définie sur $\Sigma_{a d m} \times \mathcal{E}$ (cf. équation (8)) est séparement convexe et toujours positive. Pour minimiser la fonctionnelle $F$ on utilise une méthode de relaxation : $\boldsymbol{\sigma}^{n+1}$ est obtenue en minimisant $F\left(\boldsymbol{\tau}, \mathbf{A}^{n}\right)$ par rapport à sa première variable $\boldsymbol{\tau}$ et $\mathbf{A}^{n+1}$ est obtenue en minimisant $F\left(\boldsymbol{\sigma}^{n+1}, \mathbf{B}\right)$. La deuxième étape de l'algorithme est explicite.

Pour tester les performances de l'algorithme on présente trois exemples. Dans les deux premiers tests, on considère un problème scalaire avec des mesures "parfaites" du champ de déplacement dans lequel la fonction $L_{1}$ correspond aux efforts exercés donnés sur chacun des côtés du carré unité. Ces problèmes de conductivité sont importants, p. ex. en hydrologie et ont déjà été étudiés [5]. Pour que le champ de contraintes satisfasse (4) et (5) on choisit de minimiser la fonctionnelle pénalisée (11). Dans l'exemple 2 , on teste la capacité de l'algorithme à rendre compte de singularités locales ou d'endommagement diffus. On constate que le nombre d'itérations de l'algorithme est nettement supérieur à celui obtenu dans le cas de l'exemple 1. Dans le troisième exemple, on utilise les mesures obtenues par corrélation d'images numériques lors d'un essai de traction sur une éprouvette en AU4G. Avec l'algorithme d'identification on a obtenu un module d'Young de 71GPa et un coefficient de Poisson de 0,3. Pour obtenir ces résultats on a besoin d'une seule mesure du champ des déplacements et du niveau de chargement correspondant.

The development of reliable measurement techniques of displacement fields enables one to consider identification procedures of elastic parameters of solids. The analysis presented in this Note aims at coupling 
digital image correlation with a variational method to determine fields of material parameters. Other approaches can be used (e.g., updating methods based on a constitutive law error [6], or virtual fields method [2] for which homogeneous elastic properties are sought).

\section{Displacement Measurement by Digital Image Correlation}

To evaluate the displacement field of a region of interest (ROI) with a random texture, a sequence of images is acquired for which one considers a series of sub-images (e.g., square regions) which will be referred to as Zones Of Interest (ZOIs). The aim of the correlation method is to match the ZOI in two chosen images. The displacement of one ZOI wrt. the other one is a two-dimensional shift of an intensity signal digitized by, say, a CCD camera. One considers signals $g(\mathbf{x})$ which are perturbations of a shifted copy $f(\mathbf{x}-\mathbf{u})$ of some reference signal $f(\mathbf{x})$

$$
g(\mathbf{x})=f(\mathbf{x}-\mathbf{u})+b(\mathbf{x})
$$

where $\mathbf{u}$ is an unknown in-plane displacement field assumed to be constant locally (i.e., independent of the position $\mathbf{x}$ ) and $b(\mathbf{x})$ a random noise (e.g., photon noise, readout noise, dark current noise for CCD cameras [4]). To evaluate the displacement $\mathbf{u}$, one may minimize the norm of the difference between $f(\mathbf{x}-\mathbf{v})$ and $g(\mathbf{x})$ with respect to a trial displacement $\mathbf{v}$

$$
\min _{\mathbf{v}}\|g-f(.-\mathbf{v})\|^{2}
$$

where ' ' denotes a dummy variable. If one chooses the usual quadratic norm $\|f\|^{2}=\iint_{-\infty}^{+\infty}|f(\mathbf{x})|^{2} \mathrm{~d} \mathbf{x}$, then the previous minimization problem is equivalent to maximizing the quantity $h(\mathbf{v})$

$$
h(\mathbf{v})=(g \star f)(\mathbf{v})=\int_{-\infty}^{+\infty} \int_{-\infty}^{+\infty} g(\mathbf{x}) f(\mathbf{x}-\mathbf{v}) \mathrm{d} \mathbf{x}
$$

where $\star$ denotes the cross-correlation operator. Furthermore, when $b$ is a white noise, the previous estimate is optimal. The displacement maximizing the cross-correlation product will be denoted by $\mathbf{u}^{*}$ and corresponds to an evaluation of the unknown displacement vector $\mathbf{u}$. The computation of a cross-correlation product can be performed either in the original space or by using Fast Fourier Transforms (FFTs). A subpixel algorithm is used [1].

In Fig. 1, strain measurements by using strain gauges are compared with predictions of the correlation technique. The images are taken by an 8 -bit CCD camera $(1008 \times 1016$ pixels $)$. Longitudinal and transverse strains are evaluated in a tensile test on a 2024 aluminum alloy specimen. A special setup is used to avoid spurious flexure [3]. For load levels greater than $600 \mathrm{~N}$ (i.e., an average stress of $26 \mathrm{MPa}$ ), it is observed that the flexural strains are at most $1 \%$ of the tensile strains [8]. A long-distance microscope monitors a $4 \mathrm{~mm}^{2}$ surface. A ZOI size of $64 \times 64$ pixels is chosen. The rms error is equal to $6 \times 10^{-5}$. Consequently, average strains as small as $10^{-4}$ can be measured accurately. Furthermore, it can be noted that the average shear strains (negligibly small with the setup) are found to be equal to $-10^{-5}$ with an rms error of $2.4 \times 10^{-5}$. Comparable results can be obtained with $32 \times 32$ pixel ZOIs. These data can be used to evaluate the elastic properties of the studied material. A Young's modulus of $72 \pm 3 \mathrm{GPa}$ and a Poisson's ratio of 0.3 \pm 0.03 are obtained for average tensile stresses varying between 10 and $90 \mathrm{MPa}$. These values are in good agreement with reported values for this alloy [7] (72 GPa and 0.32, respectively) and those deduced from strain measurements ( $76 \pm 0.5 \mathrm{GPa}$ and $0.33 \pm 0.005$, respectively).

With these measures, we know the in-plane displacement field $\mathbf{u}^{*} \in\left(\mathrm{H}^{1}(\Omega)\right)^{2}$ where $\Omega \subset \mathbb{R}^{2}$ denotes the ROI, some linear observations on the stress tensor $\boldsymbol{\sigma}$ (e.g., the global load level of the tensile test can be considered as a linear observation of the unknown stress field)

$$
L_{1}(\boldsymbol{\sigma})=g_{1}, \ldots, L_{N}(\boldsymbol{\sigma})=g_{N}
$$




\section{G. Geymonat, F. Hild, S. Pagano}

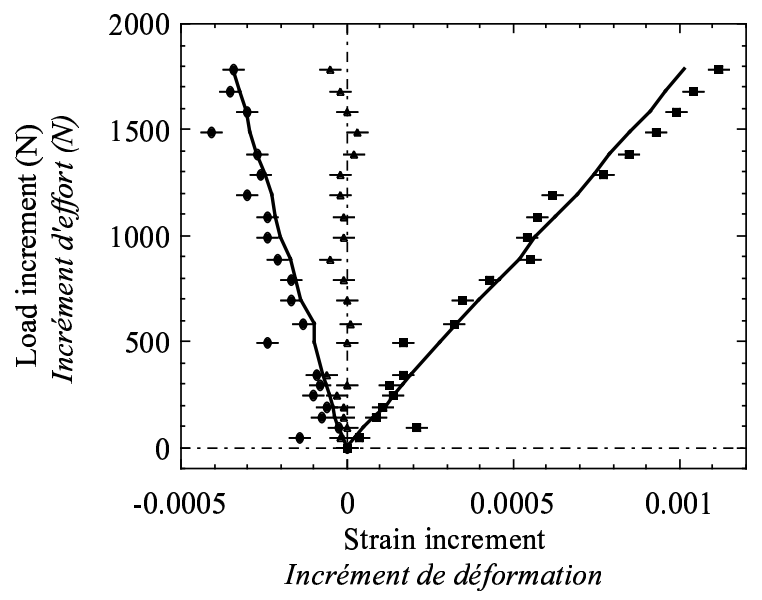

Figure 1: Strains measured by gauges (solid lines) and by digital image correlation (symbols) with a subpixel algorithm (225 ZOIs, ZOI size: $64 \times 64$ pixel ZOIs).

Déformations mesurées avec des jauges (trait continu) et par corrélation d'images numériques (symboles) avec un algorithme sub-pixel (225 ZE, taille de chaque ZE : $64 \times 64$ pixels).

and the density of volume force $\mathbf{f}$. The main goal is to find the associated elasticity tensor and the stress field without any additional assumptions. In practice the set $\Omega$ is the union of squares and the data are known at some interpolation points. For this reason, we consider that the unknown strain field $\varepsilon\left(\mathbf{u}^{*}\right)$ is piecewise linear.

\section{Formulation of the identification problem}

We say that a couple $(\mathbf{A}, \boldsymbol{\sigma})$ is a solution to the identification problem if it satisfies (4) and

$$
\begin{array}{lc}
\operatorname{div} \boldsymbol{\sigma}+\mathbf{f}=0 & \text { in } \Omega \\
\boldsymbol{\sigma}=\mathbf{A}^{-1} \varepsilon\left(\mathbf{u}^{*}\right) & \text { in } \Omega
\end{array}
$$

Let $\Sigma_{a d m}$ be the set of admissible stress fields defined as

$$
\Sigma_{a d m}=\left\{\boldsymbol{\tau} \in \mathrm{L}^{2}(\Omega) ; \operatorname{div} \boldsymbol{\tau} \in \mathrm{L}^{2}(\Omega), \operatorname{div} \boldsymbol{\tau}+\mathbf{f}=0 \text { in } \Omega, L_{1}(\boldsymbol{\tau})=g_{1}, \ldots, L_{N}(\boldsymbol{\tau})=g_{N}\right\}
$$

and let suppose that $\Sigma_{a d m}$ is not empty ${ }^{1}$. The set of admissible (elastic) compliance tensors will be denoted by $\mathcal{E}$. Two possible simple choices are

$$
\begin{aligned}
& \mathcal{E}_{1}=\left\{\mathbf{B} \in \mathbb{R}^{3 \times 3} ; B_{i j}=B_{j i}, \mathbf{B x}: \mathbf{x} \geqslant \alpha|\mathbf{x}|^{2}, \alpha>0, \forall \mathbf{x}, \mathbf{B x}: \mathbf{y} \leqslant M|\mathbf{x}||\mathbf{y}|, M>0, \forall \mathbf{x}, \mathbf{y}\right\} \\
& \mathcal{E}_{2}=\left\{B_{i j} \text { is piecewise linear } ; B_{i j}=B_{j i}, \mathbf{B x}: \mathbf{x} \geqslant \alpha|\mathbf{x}|^{2}, \alpha>0, \forall \mathbf{x}, \mathbf{B x}: \mathbf{y} \leqslant M|\mathbf{x}||\mathbf{y}|, M>0, \forall \mathbf{x}, \mathbf{y}\right\} .
\end{aligned}
$$

The most general choice would be

$$
\mathcal{E}_{3}=\left\{\mathbf{B} \in\left(\mathrm{L}^{\infty}(\Omega)\right)^{3 \times 3} ; B_{i j}=B_{j i}, \mathbf{B x}: \mathbf{x} \geqslant \alpha|\mathbf{x}|^{2}, \alpha>0, \forall \mathbf{x}, \mathbf{B x}: \mathbf{y} \leqslant M|\mathbf{x}||\mathbf{y}|, M>0, \forall \mathbf{x}, \mathbf{y}\right\} .
$$

\footnotetext{
${ }^{1}$ From an abstract point of view, an open question is to find suitable conditions on the data $\mathbf{f}, \boldsymbol{g}, \ldots, g_{N}$ in such a way that this assumption be satisfied
} 
With these notations, we define the functional $F$ from $\Sigma_{a d m} \times \mathcal{E}$ into $\mathbb{R}$ by

$$
F(\boldsymbol{\tau}, \mathbf{B})=\int_{\Omega}\left\{\frac{1}{2} \varepsilon\left(\mathbf{u}^{*}\right): \mathbf{B}^{-1} \varepsilon\left(\mathbf{u}^{*}\right)+\frac{1}{2} \tau: \mathbf{B} \boldsymbol{\tau}-\boldsymbol{\tau}: \varepsilon\left(\mathbf{u}^{*}\right)\right\} d \mathbf{x} d \mathbf{y} .
$$

LEMMA 2.1. - The following properties for the functional $F$ hold true

(i) $F(\boldsymbol{\tau}, \mathbf{B}) \geqslant 0, \forall(\mathbf{B}, \boldsymbol{\tau}) \in \Sigma_{a d m} \times \mathcal{E}$.

(ii) $F\left(\tau^{*}, \mathbf{B}^{*}\right)=0$ if and only if (6) is true with $\boldsymbol{\sigma}=\tau^{*}$ and $\mathbf{A}=\mathbf{B}^{*}$.

(iii) The functional $F$ is separately convex on $\Sigma_{a d m} \times \mathcal{E}$.

Proof: Let us first rewrite the functional $F$ as

$$
F(\boldsymbol{\tau}, \mathbf{B})=\frac{1}{2} \int_{\Omega}\left(\tau-\mathbf{B}^{-1} \varepsilon\left(\mathbf{u}^{*}\right)\right)^{T} \mathbf{B}\left(\tau-\mathbf{B}^{-1} \varepsilon\left(\mathbf{u}^{*}\right)\right) d \mathbf{x} d \mathbf{y}
$$

With this expression and since $\mathbf{B}$ belongs to $\mathcal{E}$, (i) and (ii) are obvious. For the separate convexity of $F$, we just have to prove the convexity of the function $\varphi_{1}(\mathbf{B}):=\frac{1}{2} \varepsilon\left(\mathbf{u}^{*}\right): \mathbf{B}^{-1} \varepsilon\left(\mathbf{u}^{*}\right)$ on $\mathcal{E}$ and the separate convexity of the function $\varphi_{2}(\tau, \mathbf{B}):=\frac{1}{2} \boldsymbol{\tau}: \mathbf{B} \tau$ on $\Sigma_{a d m} \times \mathcal{E}$. For $\varphi_{1}$, we can compute the second directional derivative $\varphi_{1}^{\prime \prime}$

$$
\varphi_{1}^{\prime \prime}(\mathbf{B} ; \mathbf{C}, \mathbf{C})=\left(\mathbf{C B}^{-1} \varepsilon\left(\mathbf{u}^{*}\right)\right)^{T} \mathbf{B}^{-1}\left(\mathbf{C B}^{-1} \varepsilon\left(\mathbf{u}^{*}\right)\right) \geqslant \alpha\left|\mathbf{C B}^{-1} \varepsilon\left(\mathbf{u}^{*}\right)\right|^{2} .
$$

Since $\varphi_{2}$ is non-negative by definition, it follows that $\varphi_{2}$ is always separately convex

\section{Algorithm and numerical performance}

In order to minimize the functional $F$ on $\Sigma_{a d m} \times \mathcal{E}$ a relaxation method is used: $\boldsymbol{\sigma}^{n+1}$ is obtained by minimizing $F\left(\boldsymbol{\tau}, \mathbf{A}^{n}\right)$ over its first variable $\boldsymbol{\tau}$ and $\mathbf{A}^{n+1}$ is obtained by minimizing $F\left(\boldsymbol{\sigma}^{n+1}, \mathbf{B}\right)$. This second computation is explicit. In each step of the algorithm we minimize a convex function. We illustrate the algorithm on three examples.

Example 1: To test the performance of the algorithm, we consider a scalar problem with "perfect measurements" on the unit square $\Omega=(0,1) \times(0,1)$ discretized with squares. For instance, the solution to this conductivity problem is important in hydrology and it has been solved in Ref. [5]. At the nodal points are given $u^{*}=x+y+\frac{1}{3}\left(x^{3}+y^{3}\right), f=-\operatorname{div}\left(\nabla u^{*} / a_{e x}\right)$, where $a_{e x}=1 /\left(1+y^{2}\right)$. On the boundary, the given surface force is $g=\frac{1}{a_{e x}} \frac{\partial u^{*}}{\partial n}$. We assume that $\mathcal{E}=\mathcal{E}_{1}$ and $L_{1}(\boldsymbol{\sigma})=\boldsymbol{\sigma} \cdot \mathbf{n}=g$ on all the boundaries of $\Omega$. Since the stress field solution is constrained by (5) and by $\boldsymbol{\sigma} \cdot \mathbf{n}=g$ on $\partial \Omega$, we choose to minimize the penalized functional

$$
F_{N}(\boldsymbol{\tau}, b)=F(\boldsymbol{\tau}, b)+\gamma_{1}\|\operatorname{div} \boldsymbol{\tau}+\mathbf{f}\|_{\mathrm{L}^{2}(\Omega)}^{2}+\gamma_{2}\|\boldsymbol{\tau} . n-\mathbf{g}\|_{\mathrm{L}^{2}(\partial \Omega)}^{2},
$$

where $\tau$ has continuous, piecewise linear components on the triangulation, $b$ is continuous and piecewise linear and $\gamma_{1}$ and $\gamma_{2}$ are two penalty factors. In examples 1 and 2 , we take $\gamma_{1}=\frac{1}{h}$ and $\gamma_{2}=\frac{1}{h^{2}}$, where $h$ is the mesh size. The observed convergence is $\left\|a_{n}-a_{e x}\right\|_{\mathrm{L}^{2}} \sim O\left(h^{0.57}\right)$ and $F\left(\boldsymbol{\sigma}_{n}, a_{n}\right) \sim O\left(h^{1.16}\right)$.

Example 2: To test the performance of the algorithm to capture local singularities and diffuse damage, we consider the situation where $a_{e x}=1 /\left(\varepsilon+(y-1 / 2)^{2}\right)$, where $\varepsilon$ is a positive constant, for a local singularity and where $a_{e x}=1 /(1-D)\left(1+y^{2}\right)$, where $D \in(0,1)$, for diffuse damage. One can note that the number of iterations increases when $\varepsilon$ decreases and that for $\varepsilon$ less than or equal to 0.005 we loose the convergence (cf. figure 2); for 0.005 we can obtain better results by using a refined mesh. For the other example, the number of iteration increases when $D$ tends to 1 (10 iterations for $D=0,12$ for $D=0.5$ and 86 for $D=0.999)$. 


\section{G. Geymonat, F. Hild, S. Pagano}
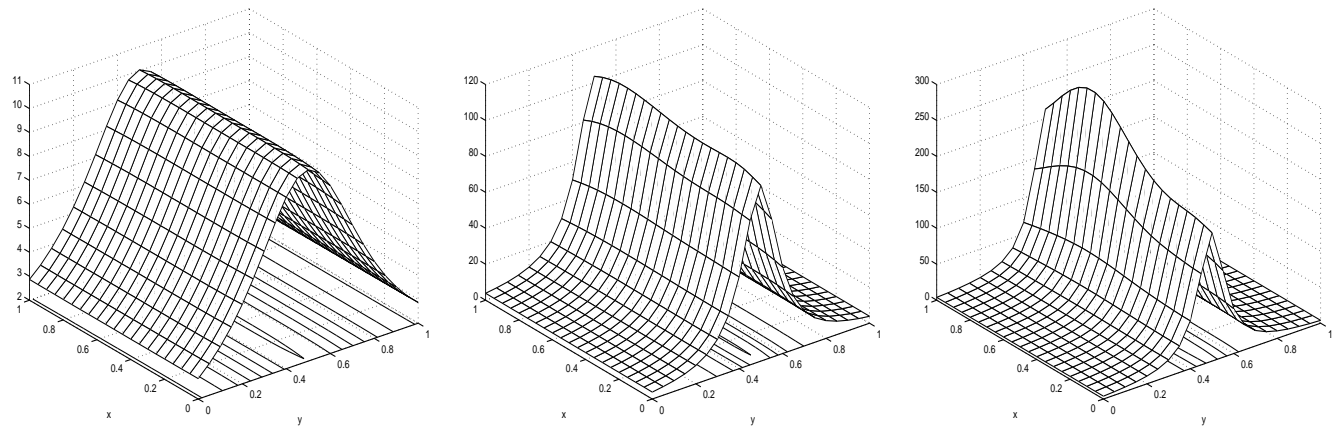

Figure 2: Computed conductivity $a_{e x}$ for different values of $\varepsilon: 0.1,0.01$ and 0.005 (400 quadrangular elements).

Conductivité $a_{e x}$ calculée pour différentes valeurs de $\varepsilon: 0.1,0.01$ et 0.005 (400 élements quadrangles).

Example 3: We use the data obtained by digital image correlation on the tensile test described in Section 1. In this case, $\Omega$ is the square corresponding to $1008 \times 1008$ pixels, $\mathbf{f}=0, L_{1}(\boldsymbol{\sigma})$ and $L_{2}(\boldsymbol{\sigma})$ are respectively the resultants of the applied tensile force on the upper and lower edges of $\Omega$. The admissible set for elastic coefficients is $\mathcal{E}_{1}$. A Young's modulus of $71 \mathrm{GPa}$ and a Poisson's ratio of 0.3 are obtained by the identification algorithm. These values are in good agreement with the results of Section 1.

The resolution of the digital image correlation technique is sufficient to allow for an identification of elastic properties of many solids. By using the variational approach used herein, or others [6, 2], one can envision a way of determining damage fields based upon the (state) coupling between elasticity and damage [7].

Acknowledgements. Remerciements.

The experiments reported herein were performed by P. Renaud during his MSc thesis.

\section{References}

[1] L. Chevalier, S. Calloch, F. Hild, Y. Marco, Digital image correlation used to analyze the multiaxial behavior of rubber-like materials, Eur. J. Mech. A/Solids 20 (2001) 169-187.

[2] M. Grediac, E. Toussaint, F. Pierron, L'identification des propriétés mécaniques de matériaux avec la méthode des champs virtuels, une alternative au recalage par éléments finis, C. R. Mécanique 330 (2002) 107-112.

[3] F. Hild, E. Amar, D. Marquis, Stress heterogeneity effect on the strength of silicon nitride, J. Am. Ceram. Soc. 75 (1992) 700-702.

[4] G. Holst, CCD arrays, cameras and displays, SPIE Engineering Press, 1998.

[5] R.V. Kohn, B.D. Lowe, A variational method for parameter identification, Math. Mod. and Num. Anal. 22 (1988) 119-158.

[6] P. Ladevèze, D. Nedjar, M. Reynier, Updating of finite element models using vibration tests, AIAA 32 (1994) 1485-1491. See also: S. Calloch, D. Dureisseix, F. Hild, Identification de modèles de comportement de matériaux solides : utilisation d'essais et de calculs, Technologies et Formations 100 (2002) 36-41.

[7] J. Lemaitre, J.-L. Chaboche, Mécanique des matériaux solides, Dunod, 1985. English translation: Mechanics of solid materials, Cambridge University Press, 1990.

[8] P. Renaud, Comportement d'un matériau composite carbone/carbone 3D sous chargement uniaxial, MSc report, ENS de Cachan, 2000. 